\title{
NODULE FORMATION IN RHEUMATIC DISEASE
}

\author{
BY \\ G. D. KERSLEY, H. J. GIBSON
and
}

M. H. L. DESMARAIS

From the Royal National Hospiral for Rheumatic Diseases, Bath

The literature on nodule formation in rheumatic disease is confused by the absence of co-ordination of clinical data and pathological material. Nodules of one sort or another are found in many rheumatic syndromes, and also in conditions which are barely within the scope of that designation. Parkes Weber (1943) classified nodules into eight types: those occurring in acute rheumatism, rheumatoid arthritis, gout, xanthomata, calcinosis, amyloidosis, mucinous (in thyroid dysfunction), and those occurring in the Ehlers-Danlos syndrome of laxity, abnormal elasticity, atrophy, and friability of the skin and ligaments. While the types of nodule found in acute rheumatism and rheumatoid arthritis are becoming fairly well defined (Dawson, 1933; Collins, 1939; and Bennett, 1943), there is still much debate on their structure in fibrositis, Copeman and Ackerman (1944) believing them to be fatty herniations, and Elliott (1944) supporting the view that they are only areas of spasm of muscle fibres.

It was, therefore, decided to keep separately careful clinical records and biopsy reports on all cases of rheumatic or pseudo-rheumatic disease where nodules were definitely palpable, and later to classify them clinically, comparing their clinical diagnoses with the findings of the pathologist. Twenty-seven cases have been so examined.

\section{CASE 1}

A farmer, aged 24, gave a history of typical tophaceous gout of five years' duration, with frequent acute attacks and periods of complete remission. Tophi were present in both ears, elbows, and hands, and in the right knee. Radiographs showed the typical appearances of gout, with "punched-out" areas but no generalized osteoporosis or loss of joint space. Over a period of three years the blood uric acid varied between $3.8 \mathrm{mg}$. and $8 \mathrm{mg}$. per $100 \mathrm{c.cm}$. of blood. The haematocrit reading was persistently normal or above normal, and the corrected suspension stability test (C.S.S.) fluctuated between $54 \%$ and $66 \%$. A nodule on the right elbow was excised for section. As he was an adopted child no family history was available.

Macroscopically, the tissue excised consisted of a fibrous wall surrounding a loculated cavity filled with a paste of biurate crystals.

Microscopic Findings (Fig. 1).--Underlying the true

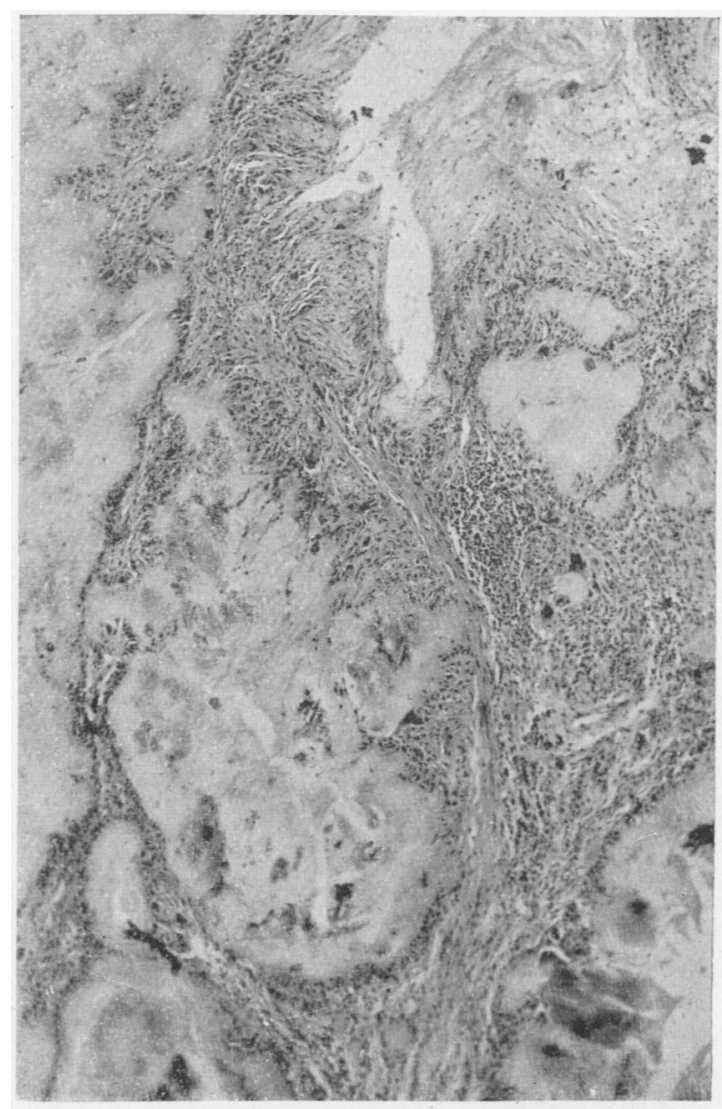

FIG. 1.-A subcutaneous nodule from a typical case of gout (Case 1). It consists of fibrous septa enclosing areas of hyaline amorphous material in which biurate crystals are present. Along the septa there is a marked fibroblastic reaction. Giant cells of foreign-body type and lymphocytes are also seen. Haematoxylin and eosin. $\times 100$.

skin, fibrous tissue strands were present forming loculi of varying size and rounded shape, and containing hyaline amorphous material impregnated with acicular crystals of biurate. The walls of these spaces showed a proliferation of young fibroblasts, often with a radial alignment similar to those seen round necrotic areas in the nodule of rheumatoid arthritis. Also present were many foreign-body giant cells of small size, containing up to six nuclei. The appearances were those of a subcutaneous gouty tophus. 
CASE 2

A man, aged 68, with no family history of gout, first noticed swelling of the proximal interphalangeal joint of his left index finger fifteen years ago. The swelling had gradually increased in size to that of a tangerine, and the other fingers became similarly affected. Two years later the condition spread to the toes, and then to the olecranon bursae of the elbows and the right knee. There were no acute attacks or remissions, and there was but little pain, but gradually tophaceous material became apparent. Six years ago one of the toes was so deformed and swollen that it had to be amputated, and for the same reason a finger was removed four years ago. About this time one of the olecranon bursae burst, tophaceous material bespattering the wall when the elbow was flexed. The patient was, apart from the joint condition, physically fit and had slowly gained in weight. The blood uric acid seven years ago was $6 \mathrm{mg}$. per $100 \mathrm{c.cm}$. of blood, and the plasma uric acid is now $9.0 \mathrm{mg}$. per $100 \mathrm{c} . \mathrm{cm}$. The blood cholesterol was $150 \mathrm{mg}$. per $100 \mathrm{c.cm}$. The nodule was a typical subcutaneous gouty tophus. The dermis showed dense round-cell accumulations in close relation to the vessels. Lymphocytes were the predominant cell. The main mass of the nodule consisted of areas of hyaline degeneration heavily infiltrated with biurate crystals and outlined by fibrous septa containing fibroblasts, mesenchymal cells, and many giant cells.

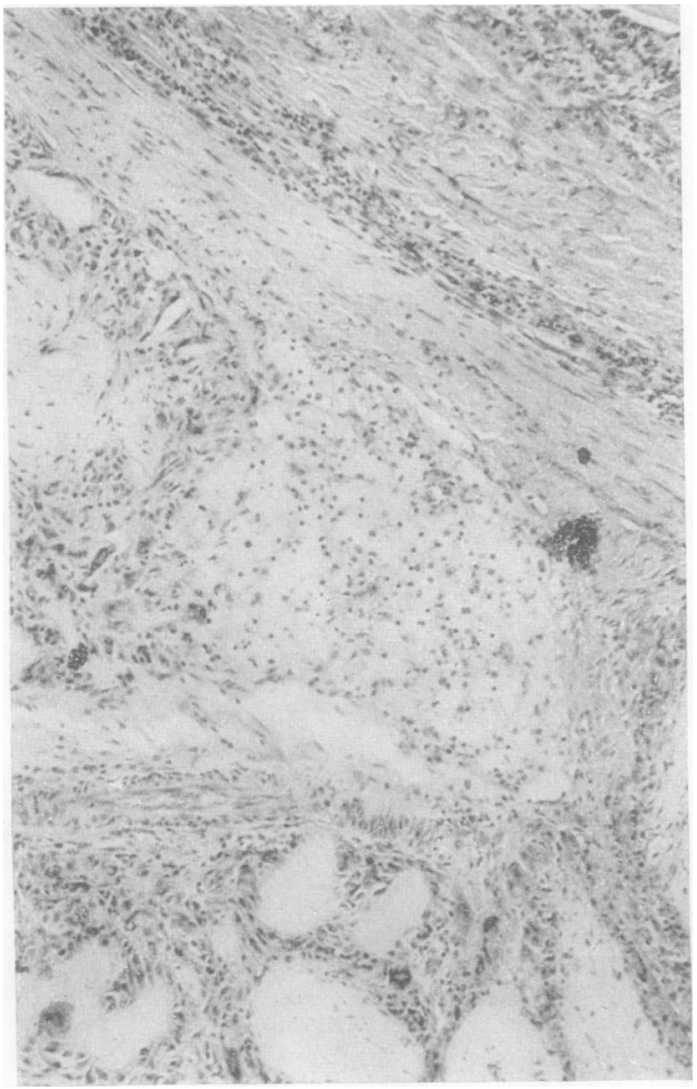

FIG. 2.-Subcutaneous nodule from toe of a typical case of advanced gout (Case 2). Among the usual cellular features shown in Fig. 1, was found an island of large polyhedral cells with small, round, darkly stained nuclei and vacuolated cytoplasm. They resemble morphologically the "foam cells" seen in Case 14. Haematoxylin and eosin. $\times 100$.
In one area, in the space where three rounded necrotic areas met, was seen a group of large polygonal cells with small round nuclei towards the centre (Fig. 2). The nuclei contained a varying amount of chromatin and an eccentric nucleolus. The cytoplasm was granular and vacuolated, and the thin nuclear membrane clearly defined. These cells closely resembled the "foam cells" described by Fletcher (1946). They have not been found in other gouty material.

CASE 3

A docker, aged 55, gave a history of rheumatoid arthritis of three years' duration. The joints were symmetrically involved, with a mild degree of fusiform swelling of the fingers and slight muscle wasting of the forearms and interossei. There had been no marked loss of weight. The condition on admission was fairly active, as shown by the decreased C.S.S. $\left(56^{\circ}{ }_{0}^{\prime}\right)$, the low haematocrit $(38 \%)$ and acute pains in the knees, feet, and hands. Radiographs of the hands were typical of rheumatoid arthritis. A nodule of two years' duration on the left elbow was excised for examination. The section showed a large nodule $20 \mathrm{~mm} . \times 18 \mathrm{~mm}$. lying in and deep to the cutis. The skin was normal. At the level of the deeper sweat glands the nodule proper commenced. It consisted of fibrous tissue in which were numerous areas of necrosis surrounded by a palisade layer of radially arranged mesenchyme cells of fibroblastic type. The necrotic foci showed an inner zone of complete necrosis of slightly basophil tint, and in some cases this showed fissures and commencing cavitation. Surrounding the area of complete necrosis there was a zone, adjacent to the palisade layer, in which destruction of the collagen fibres was incomplete and which showed the reticulated structure of fibrinoid degeneration. Within all the necrotic zones, which appeared to be continuous with one another by narrow bands of necrosis, nuclear fragments were present. At the periphery of the nodule fibrous tissue was seen with broad collagen bundles and numerous vessels. Many of the latter showed thickened walls; and, where a necrotic area was in close proximity, complete obliteration of the lumen had occurred. The appearances were typical of the rheumatoid arthritis nodule as described by Dawson (1933) and Collins (1937).

\section{CASE 4}

A man, aged 42, gave a history of typical rheumatoid arthritis of thirteen years' duration, and a recent flare-up. The condition was fairly active as shown by the C.S.S. $\left(63^{\circ}{ }_{0}\right)$. There was no secondary anaemia, but he had lost some weight before admission. The radiographs were typical of rheumatoid arthritis with early secondary osteo-arthritic changes. He had had two courses of gold therapy with fairly good response. A nodule about the size of a walnut, which had first appeared six years before on the right elbow, was excised under a local anaesthetic and was found to be typical of rheumatoid arthritis, as described in Case 3. Very extensive necrosis was present, with widespread early disintegration and commencing liquefaction of the necrotic tissue to form small cystic cavities. The extent of necrosis due to coalescence of separate foci is consistent with the six years' duration of this nodule.

\section{CASE 5}

A man, aged 64, gave a history of rheumatoid arthritis of ten years' duration. On admission the condition was active, with a lowered C.S.S. of $65 \%$, and loss of weight. The blood uric acid was normal, and the Berger Test 
negative. Repeated examinations of the sputum showed no tubercle bacilli. Radiographs showed the appearance of advanced rheumatoid arthritis. There were multiple nodules on the elbows, sacrum, and scalp. A nodule on the left elbow was excised.

On section the nodule showed an inner zone of very dense fibrous tissue with few nuclei and an appearance of scar tissue. In this were a few elongated masses of eosinophil fibrinoid material with a surrounding zone of radially arranged fibroblasts and larger primitive mesodermal cells as seen in rheumatoid nodules. The peripheral zone was vascular and the vessels were associated with a copious lymphocytic infiltration. The lymphocytes were para-vascular in their distribution, and the appearances resembled closely those found in nerve and muscle in rheumatoid arthritis. Thus the nodule, while definitely of rheumatoid type, presented unusual features-a condensation of fibrous tissue, and abundant round-cell reaction around vessels in the peripheral zone.

\section{CASE 6}

A commercial traveller, aged 40 , gave a history of rheumatoid arthritis of three years' duration. The right ankle was the first joint to be involved, but within three years the knees, elbows, and hands were affected. The C.S.S. was $61 \%$; the haematocrit $40 \%$, and the blood uric acid $3.4 \mathrm{mg}$. per $100 \mathrm{c}$. cm. of blood. Radiographs of the hands showed changes of rheumatoid type with translucent areas simulating gout. From the onset the patient developed nodules on the middle finger of the left hand. Within a year they were present on the knees and elbows, and a nodule on the right elbow was excised for section. The histology was typical of rheumatoid arthritis without any unusual features.

\section{CASE 7}

A man, aged 49, gave a history of rheumatoid arthritis of five years' duration. The C.S.S. was $63^{\circ} \%$, the haematocrit $45^{\circ}$, and blood uric acid $1.8 \mathrm{mg}$. per $100 \mathrm{c.cm}$. of blood. A subcutaneous nodule was excised from the elbow under local anaesthetic. The nodule was typical of rheumatoid arthritis, as previously described.

\section{CASE 8}

A housewife, aged 41, had had clinical signs of atypical rheumatoid arthritis for five years. She gave a history of generalized pains in all her joints except the hips and knees, the onset following soon after an air raid. The disease was still active at the time of examination, with progressive loss of weight and a decreased C.S.S. (67\%). There was no anaemia and the plasma uric acid was normal, $5 \cdot 1 \mathrm{mg}$. per $100 \mathrm{c.cm}$. of blood. Radiographs of the hands showed changes of gouty type with well marked "punched out" areas. There was, however, no family history of gout. Subcutaneous nodules of the size of walnuts appeared on the elbows two years before admission, and one of these was excised for microscopic examination. The tissue showed the characteristic structure of a rheumatoid arthritic nodule. It was an early example, showing numerous proliferative foci, fibrinoid, and necrotic lesions, with the usual radial fibroblastic reaction. There was no suggestion of gout.

\section{CASE 9}

A park-keeper, aged 56, appeared clinically to have had acute rheumatoid arthritis for three years. Throughout the illness the haematocrit had, however, been normal, the C.S.S. fluctuated between $59 \%$ and $79 \%$ and the blood uric acid between $2.5 \mathrm{mg}$. and $4.2 \mathrm{mg}$. per 100 c.cm. of blood. There was no history of gout or rheumatism in the family. Two years after the onset a subcutaneous nodule appeared in the right elbow, and since then multiple subcutaneous nodules had appeared over the ulnar surface of both forearms, the scapulae, iliac crests, and patellae, varying in size from a small pea to a walnut. A nodule was excised from the right elbow for section and examination. The section showed the characteristic structure of a rheumatoid arthritic nodule, with extensive areas of necrosis. Giant cells were numerous in some fields at the margin of the necrotic zones.

CASE 10

A transport driver, aged 39 , gave a history of sudden onset of pain and swelling of hands and fingers four years previously. At about the same time painful subcutaneous nodules appeared on the elbows. These had gradually grown bigger, and at the time of excision had reached the size of large cherries. A year previously he had developed thyrotoxicosis with loss of weight and further involvement of the left shoulder, ankles, and jaws. A part al thyroidectomy was performed, and since then the patient's condition had improved. On admission there was no secondary anaemia, the C.S.S. was slightly raised $(73 \%)$ and the plasma uric acid was $4.7 \mathrm{mg}$. per $100 \mathrm{c.cm}$. Radiographs of the hands showed changes of rheumatoid arthritic type. The section was taken from a nodule from the right elbow and showed a typical rheumatoid arthritis structure. In the true skin lymphocytic foci were seen round and near small arteries. Arteritis was present in many of the smaller vessels.

\section{CASE 11}

A retired Army pensioner, aged 56, gave a history of arthritis of the rheumatoid type of fourteen years' duration. The knees, elbows, and wrists were the joints mostly affected. There was flexion, deformity and marked limitation of movement. The C.S.S. was normal ( $86 \%)$, there was no anaemia (haematocrit $50^{\circ}$ ), and the blood uric acid was $4.2 \mathrm{mg}$. per $100 \mathrm{c} . \mathrm{cm}$. of blood. A small nodule had been present on the right elbow for four years and was recently getting smaller. This was excised for section. It consisted of fibrous tissue and fat. There was some slight leucocytic infiltration and a few areas of hyaline degeneration, but no fibrinoid change, necrosis, or evidence of characteristic rheumatoid reaction. Patches of haemorrhage were present, and a cleft ran through the middle of the nodule, lined in part by a flattened layer of fibrous tissue. The histology was that of a traumatic nodule commencing to form an adventitious bursa.

\section{CASE 12}

A printer's foreman, aged 51, gave a history of gradual onset of pain and stiffness in the right elbow and left knee twelve years before admission. He continued with his work for another two years, when he noticed tha " his memory was deteriorating and that he could not grasp things quickly"; his speech became slurred and his voice husky. His hair and the outer halves of his eyebrows were rapidly thinning out, and over a period of four months he had put on three stone in weight. $\mathrm{He}$ was diagnosed as suffering from myxoedema, and thyroid was administered, with great improvement in all his symptoms. Nine years ago he developed pain and swelling of his hands and fingers and feet; he gradually developed all the signs and symptoms of rheumatoid arthritis, with a C.S.S. of $64 \%$, fusiform swelling of 


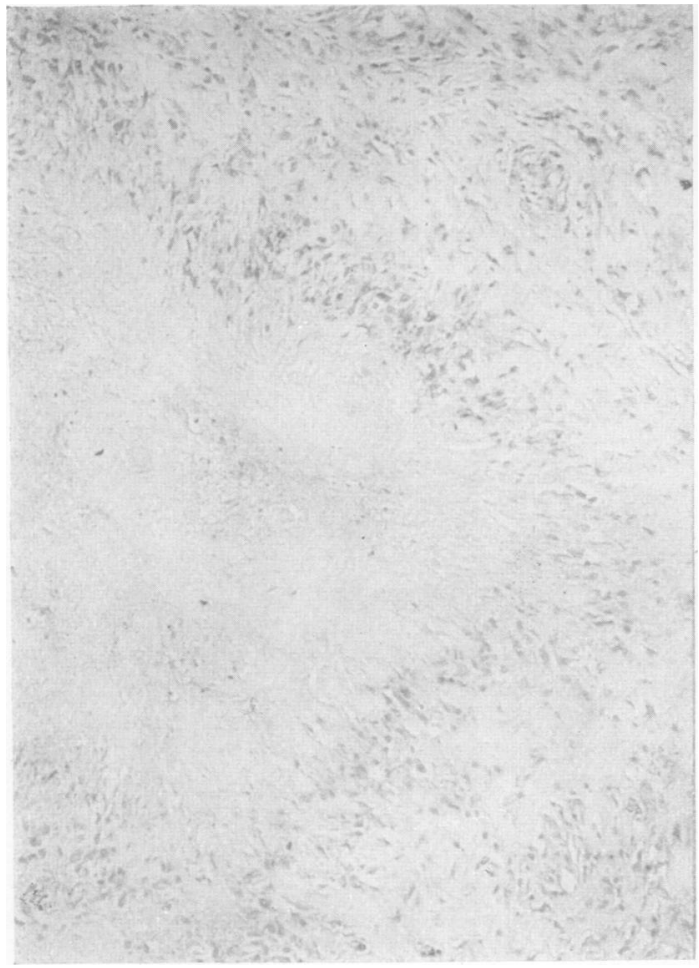

FIG. 3.-A subcutaneous nodule from Case 12. This illustrates the typical rheumatoid focus consisting of central necrotic zone surrounded by a palisade layer of radially arranged mesenchymal cells, within a fibrous mass. Haematoxylin and eosin. $\times 100$.

fingers, and flexion deformity of elbows and knees. The blood uric acid was $4 \cdot 2 \mathrm{mg}$. per $100 \mathrm{c} . \mathrm{cm}$. of blood; the haematocrit $40^{\circ},{ }_{\circ}$, the blood cholesterol was raised to $287 \mathrm{mg}$. per $100 \mathrm{c.cm}$. and his basal metabolic rate was 36. At the time of admission his general condition had improved slightly, and he was keeping a constant weight on a grain of thyroid daily. The blood cholesterol was normal (143 mg. per 100 c.cm.) the C.S.S. was $58 \%$, the haematocrit $35 \%$, and the Berger test negative. Radiographs of the hands showed typical changes of rheumatoid arthritis. A nodule which had been present on the right elbow for eight years was excised under a local anaesthetic.

The nodule was $23 \mathrm{~mm}$. $\times 18 \mathrm{~mm}$. and macroscopically it showed a number of yellow areas 2 to $3 \mathrm{~mm}$. in diameter scattered towards one end, while the structure elsewhere was of usual fibrous nature. Microscopically (Figs. 3 and 4) a typical rheumatoid nodule structure with many small necrotic foci and radially arranged fibroblasts was seen in one part of the tissue. Elsewhere the structure was quite different. The palisade layer was much less definite, the cells being smaller and less regularly arranged. The central necrotic zone was heavily infiltrated by 'cholesterol. In stained sections this was seen as a loose meshwork of clefts with narrow bridges of amorphous hyaline material separating them. The yellow zones in the fresh material, when scraped, yielded abundant cholesterol crystals. Adjacent to the areas of lipoid infiltration there were giant cells of foreignbody type. These showed abundant cytoplasm and appeared in some cases to be attempting to engulf the

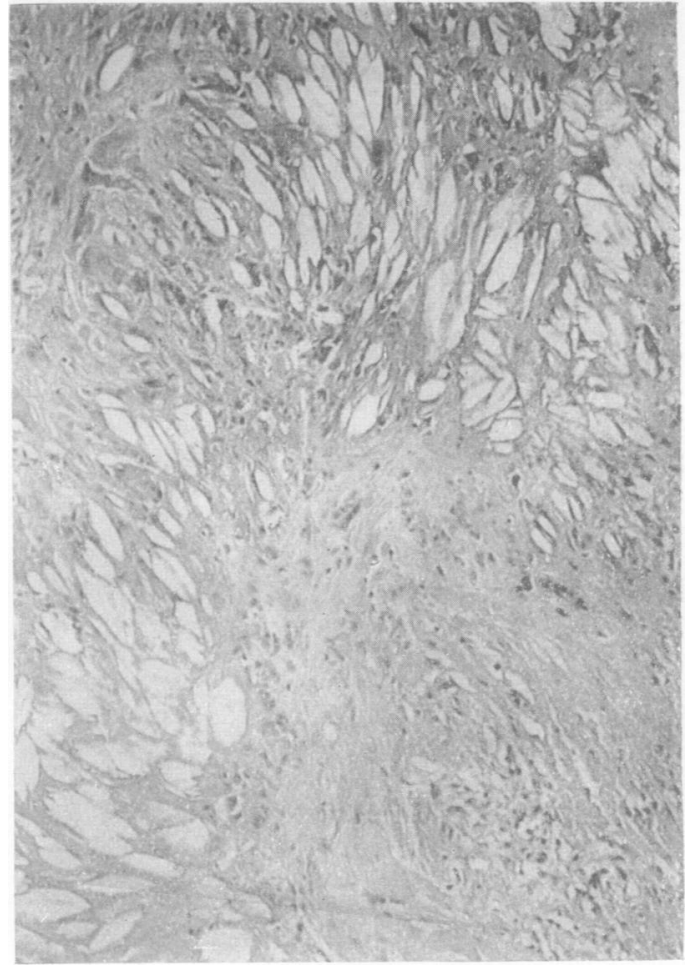

FIG. 4.-Another part of the same nodule as seen in Fig. 3 (Case 12). Extensive cholesterol infiltration is present, with a giant cell reaction. In preparing the section the cholesterol has been dissolved, leaving large fusiform clefts in the tissues. Cholesterol crystals were demonstrated in the fresh material. Haematoxylin and eosin. 100.

adjacent cholesterol. In that part of the nodules where the cholesterol was situated the surrounding fibrous tissue was more hyaline and less cellular than elsewhere. No "foam cells" were seen, but the nodule in this case appeared to have much in common with those described by Fletcher (1946), in that there was an association of lipoid deposition with an atypical rheumatoid histology in some parts, while elsewhere the picture was typical of rheumatoid arthritis.

\section{CASE 13}

A boiler hand, aged 53, gave a history of increasing pain and stiffness of the knees, hands, and fingers for four years. He had been very much overweight (19 stone), with a myxoedematous appearance, bilateral genu valgum, and abnormal deposition of fat round the hips and thighs. He reacted well to thyroid, gr. 2 daily, by steady loss of weight and increased feeling of wellbeing. The C.S.S. was decreased $(62 \%)$, but there was no anaemia, and the plasma uric acid was $5.0 \mathrm{mg}$. per $100 \mathrm{c.cm}$. Radiographs of the knees showed changes of osteo-arthritic type. Multiple nodules had appeared along the ulnar borders of the forearms eighteen months before admission, and a nodule was excised from the left elbow for microscopic examination. The section (Fig. 5A, B) showed (1) rheumatoid arthritic necrotic foci in one small area; (2) two cholesterol foci of unusual appearance, oval, with concentric layers of hyaline eosinophilic fibrous tissue with commencing cavitation and cholesterol deposits in the centre; (3) throughout the true skin, subcutaneous fat and fibrous tissue there 


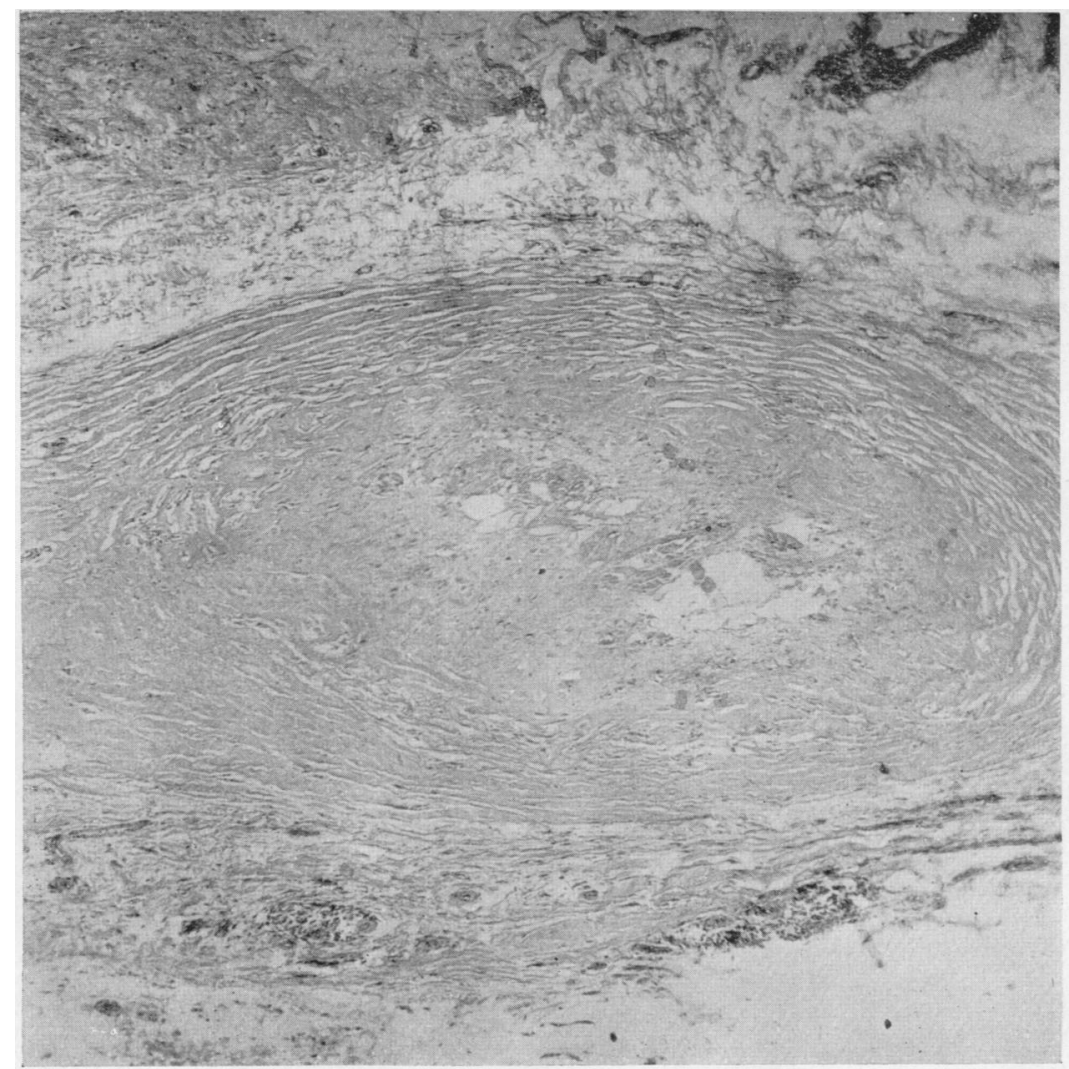

Fig. 5A.-Subcutaneous nodule from Case 13, showing an oval mass of dense hyaline fibrous tissue, in the centre of which are cholesterol clefts. No palisade layer of mesenchymal cells is present. Haematoxylin and eosin. $\times 100$.

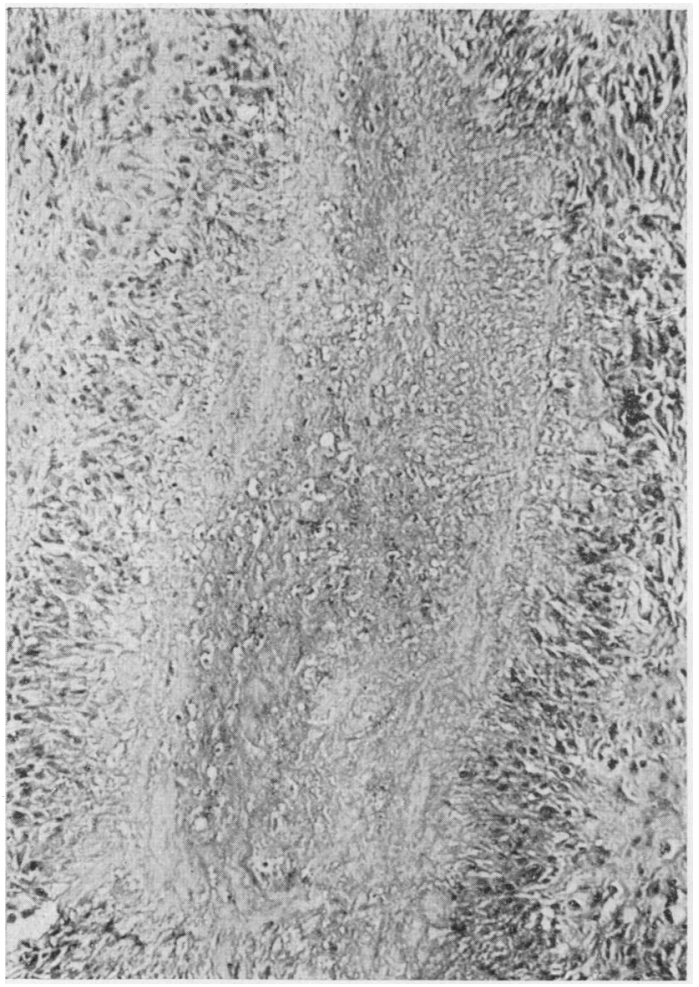

FIG. 5B-Another field from the same specimen as $5 \mathrm{~A}$ showing typical rheumatoid structure. Haematoxylin and eosin. $\times 100$.

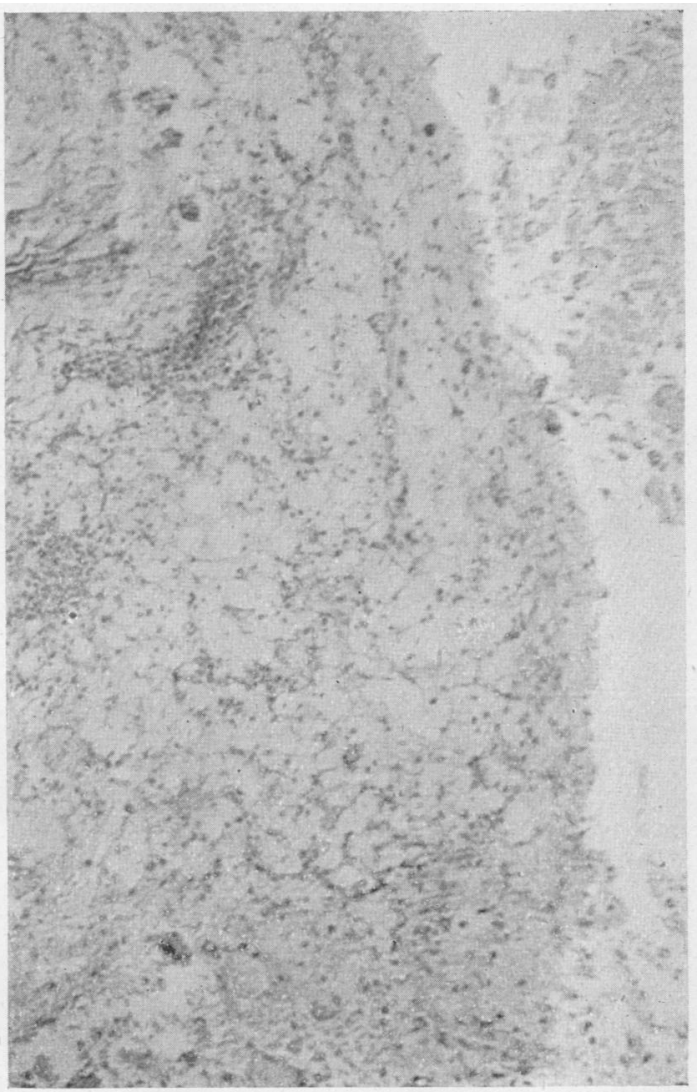

FIG. 6.-Mass from shoulder region of a fatal case of rheumatoid arthritis (Case 14). It consists mainly of necrotic tissue containing lipoid, but patches of large vacuolated "foam cells" are also seen. Haematoxylin and eosin. $\times 100$. 
were large peri- and para-vascular cell accumulations consisting of lymphocytes, plasma cells, and some polymorphs, comparable in extent with the Allison and Ghormley nodes of synovial membrane.

\section{CASE 14}

A male civil servant, aged 48 , who had suffered from severe rheumatoid arthritis for nine years, was described in our previous paper on muscle changes in rheumatoid arthritis (Gibson, Kersley, and Desmarais, 1946; Case 10).

Necropsy.-At necropsy he was found to have a broken-down nodular mass in the region of the right shoulder, which on section showed "foam cells" containing cholesterol (Fig. 6). Some fields bore a striking resemblance to some of those seen in a nodule from the advanced case of gout (Case 2, Fig. 2). Adjacent to the shoulder joint there was a sausage-shaped mass which consisted of a fibrous capsule enclosing a soft yellow greasy necrotic material. Sections showed, in addition to granular amorphous debris: (1) cholesterol clefts in hyaline fibrous tissue; (2) areas of large rounded or polygonal cells with small, darkly stained nuclei and welldefined cell membrane ; the cytoplasm was vacuolated; they resembled closely the "foam cells" described by Fletcher (1946) in a rheumatoid nodule, and also those seen in the nodule from Case 2.

\section{CASE 15}

A chairmaker, aged 52, had received a pension from 1918 to 1920 for "rheumatism" in the left shoulder. Two years before the biopsy was performed, there had been a gradual onset of pain in the left shoulder, both elbows, both hands, and wrists. The pain was never severe, and there was no history of acute episodes, though he had had pain and swelling in the big toe after walking. On admission he showed an atypical picture of rheumatoid arthritis. The C.S.S. was $72^{\circ} \mathrm{c}$, the haematocrit $47 \%$, and blood uric acid $2.3 \mathrm{mg}$. per 100 c.cm. Radiographs of the hands showed changes of the rheumatoid arthritic type, with features suggestive of gout. There was, however, no history of gout in the family. A subcutaneous nodule was excised from the right elbow for section and examination. It showed the characteristic appearances of a rheumatoid arthritic subcutaneous nodule. Numerous areas of necrosis were present with radially arranged mesenchymal cells surrounding them. The necrotic foci had coalesced, producing very large areas in which liquefaction had occurred with cavity formation.

\section{CASE 16}

A collier, aged 49, gave a history of twenty-one years of acute attacks of joint pains and swelling with periods of complete remission between the attacks. There had never been any appreciable loss of weight. The last attack was a month before admission, when the hands, elbows, and knees had been affected. The C.S.S. was slightly decreased $\left(74^{\circ}{ }_{0}\right)$ but the haematocrit was normal $\left(44^{\circ} \%\right)$. The plasma uric acid was $4.2 \mathrm{mg}$. per 100 c.cm., and the blood cholesterol of $190 \mathrm{mg}$. per $100 \mathrm{c.cm}$. was also normal. Radiographs of the hands showed "punched out" areas suggestive of gout, but clinically the hands were of the rheumatoid type. There was nothing relevant in the family or past history. At the time of the last attack a small subcutaneous nodule the size of a pea appeared in the left elbow. This was excised, and examined and showed the characteristic changes of a rheumatoid arthritic nodule. The nodule was a very early example. Over much of the section the changes were those of fibroblastic proliferation with small patches of fibrinoid change among the young fibroblasts. In two zones, however, necrosis had occurred and the appearances were typical.

\section{CASE 17}

A traveller, aged 56, who had for many years been rather depressed, introspective, and dyspeptic, gave a history that after the shock of a "blitz", three years ago, he began to have pain in his feet, spreading to the hands and elbows. Shortly afterwards nodules started to appear, first on the right and then the left elbow, over the interphalangeal joints, on the right patella, left tendo achillis, and over the left eyelid. When once they appeared they grew to sizes varying from that of a pea to a walnut and then remained stationary. Neither pain nor tenderness were features of the nodules. There was little swelling of the joints, but ulnar deviation of the fingers gradually became apparent (Fig. 7). Exacerbations were noticed to be associated with worry. There was some tenderness in certain muscle groups and the intensity of this varied greatly, an area being extremely painful and even showing some swelling for a few days at a time. There was a little restriction of movement of the shoulders, but otherwise mobility was nearly normal. No septic focus was discovered, and, though dyspepsia was a marked feature, radiographs of the gall bladder and stomach were normal. There was little change in weight. The C.S.S. had decreased from $71^{\circ}$ o to $59^{\circ}$ and the haematocrit from $46^{\circ}{ }_{0}$ to $42^{\circ}{ }_{0}^{\circ}$. The blood uric acid increased from $4.2 \mathrm{mg}$. to $5.0 \mathrm{mg}$. per $100 \mathrm{c.cm}$. Radiographs of the hands showed "punched out " areas very similar to those seen in gout (Fig. 8), but there was little, if any, clinical improvement on giving colchicum in full doses. A nodule was excised from the left elbow and was found to be typical of rheumatoid arthritis (Fig. 9). The patient was then given a short course of aurotherapy without benefit, and he has recently had some deep $x$-ray therapy for his hands, with apparently some improvement, no new nodules having appeared and some seeming to be a little smaller.

\section{CASE 18}

An Army officer, aged 25, gave a ten rnonths' history of acute rheumatic fever with rheumatic carditis, following on repeated attacks of sore throat. At the same time multiple nodules appeared on the dorsum of the hands, feet, knees, elbows, and the back of the head. Three months later, when the sedimentation rate was normal and his general condition was improving, a fresh crop of nodules appeared and there was some suspicion of fusiform swelling of the fingers with muscle wasting of the interossei of the hands. Radiographs of the hands cight months after the onset of symptoms showed obvious osteoporosis, and a month later the nodules were still present though the sedimentation rate and haematocrit were still normal. His general condition was steadily deteriorating, and examination of the heart showed both aortic and mitral valvular defects. He had lost a quarter of a stone in weight, and the epitrochlear glands were palpable but the spleen was not felt. He was not improved by full doses of salicylates.

A nodule from the left elbow was excised (Fig. 10). It showed a very cellular structure. Young fibroblasts and undifferentiated connective-tissue cells were found in large numbers, with collagen fibres which were undergoing patchy fibrinoid change in many areas. These were conspicuous as bright red-staining zones in the section stained by Masson's method. Some connectivetissue cells were often large, with one, or in certain cases 
Fig. 7.-Hands of Case 17. There were many features of gout, but examination of a nodule showed the typical appearance of rheumatoid arthritis.

FIG. 8.-Radiograph of the hands of Case 17, showing changes, including "punched out" areas, similar to those frequently seen in gout.

FIG. 9.-Nodule showing rheumatoid reaction in a case showing chemical, biochemical, and radiological features suggestive of gout. A focus of necrosis and fibrinoid change is seen, surrounded by radially arranged fibroblasts (Case 17).
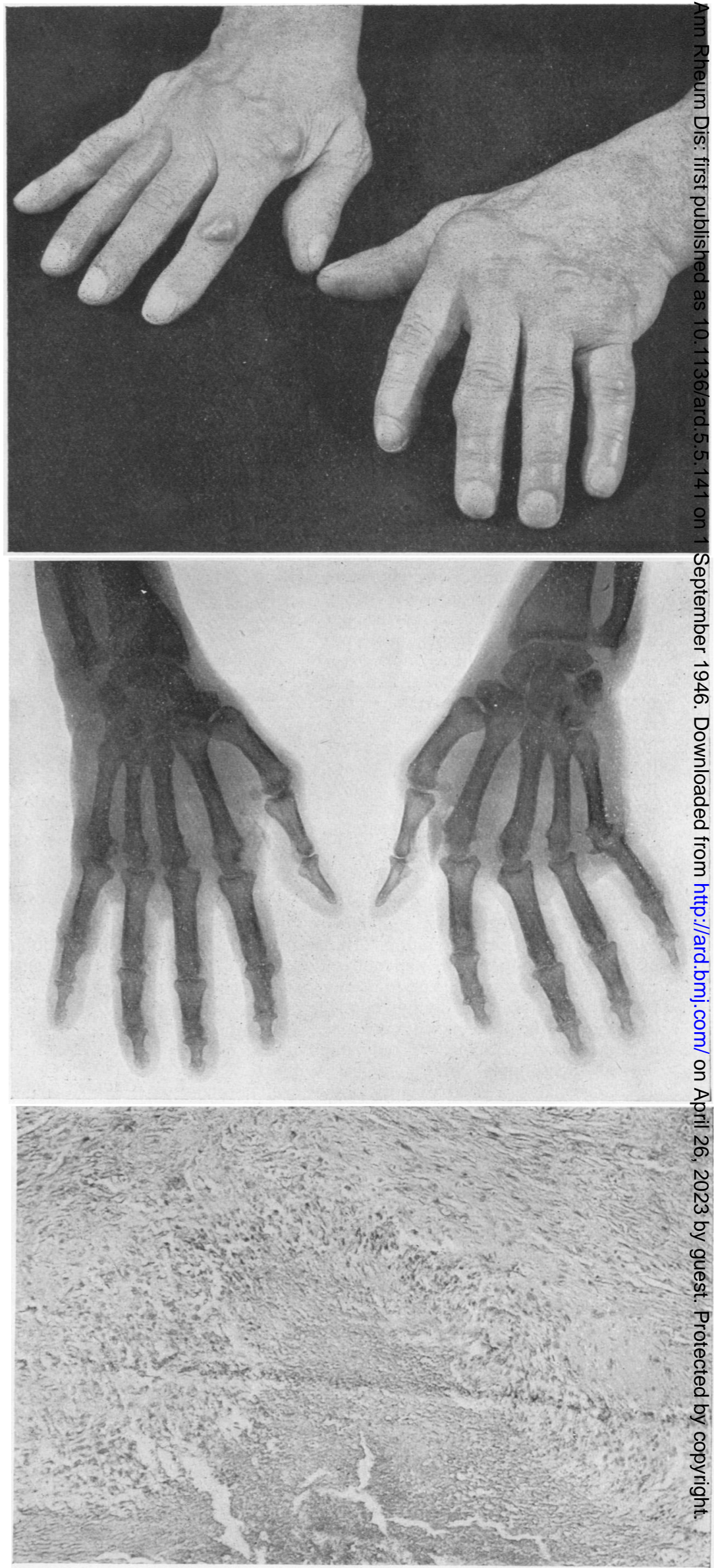
two or three, nuclei of rounded or irregular shape. Vessels were numerous and they showed the thick, almost cuboidal endothelial lining described by Collins (1937). Throughout the whole mass there was a light infiltration with polymorphonuclear neutrophil cells. One considerable area of necrosis was present, comparable to those seen in rheumatoid arthritis, but the typical radial zone of fibroblasts was not present. The appearances were those of an acute rheumatic nodule, but it was somewhat atypical in its large size $(15 \mathrm{~mm}$.

$12 \mathrm{~mm}$.) and the presence of frank necrosis.

CASE 19

A sawyer, aged 47 , gave a history of recurrent attacks of pain in back and legs of three years' duration. There was no history of past trauma or infection. He was gaining weight but still complained of generalized muscular pain. The C.S.S. and haematocrit were normal, the blood uric acid was $3.6 \mathrm{mg}$. per $100 \mathrm{c.cm}$., and the Berger test negative. Several subcutaneous nodules in the trapezius, the left upper arm and left thigh could be felt, and one of these was excised for section. The excised tissue showed skin with a lobulated fatty mass underlying it. Apart from slight congestion it showed no abnormality. Fibrous tissue was scanty, and no round-cell inflammatory reaction was seen. The nodule was lipomatous.

\section{CASE 20}

A civil servant, aged 59, gave a

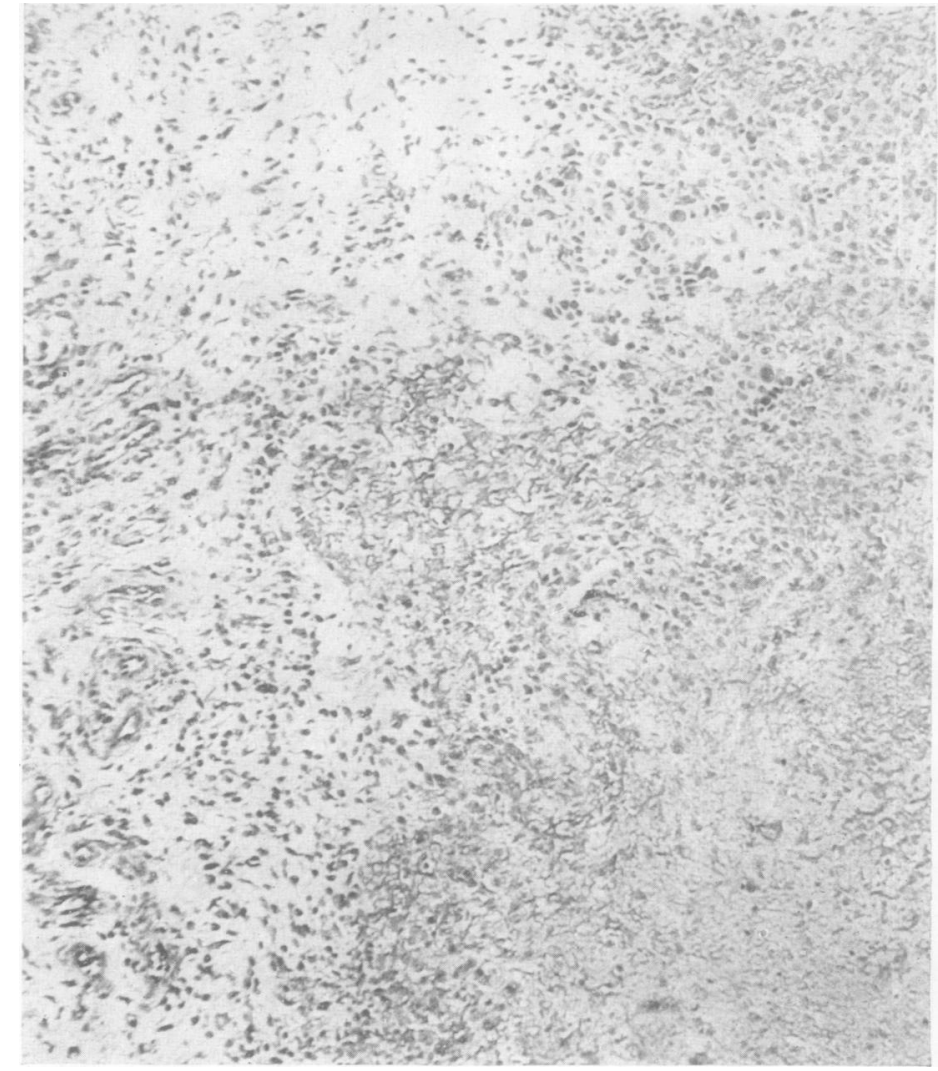

FIG. 10.-Subcutaneous nodule from a case of acute rheumatism (Case 18). An area of fibrinoid degeneration is present in young oedematous fibrous tissue. This latter is extensively infiltrated with lymphocytes, polymorphs, and undifferentiated connective-tissue cells. There are also small giant cells resembling those usually seen in the Aschoff nodule. Haematoxylin and eosin. $\times 100$. history of intermittent attacks of lumbago of eight years' duration. He had had a lot of domestic trouble and was not satisfied with his employment. He had spent four months in Knowle Mental Hospital. On examination there was some tenderness in the lower lumbar region, with limitation of movements of the spine. A radiograph of the spine showed slight lipping of the lumbar vertebrae. The C.S.S., haematocrit, and blood uric acid were all normal. The Berger test was negative. There were several flattened mobile tumours about 1 in. in diameter in the outer aspect of both thighs and forearms: one of these was excised for section, and was found to have the structure of a lipoma. It was quite separate from the overlying skin and was lobulated with thin fibrous capsule and septa. No inflammatory reaction was noted.

CASE 21

A woman, aged 28, gave a year's history of sudden onset of pain in the lower back. Since then she had had a dull aching pain in the lower back and neck and shoulders, with an exacerbation of symptoms during the last month. There was no history of infection or trauma. On examination the trapezii were tender, and multiple small nodules could be felt in the substance of the muscle and along the iliac crests on both sides. The haematocrit, sedimentation rate, and blood cholesterol were all normal. A small nodule deep in the gluteal fascia was excised under local anaesthesia, and was found to be an encapsulated lobule of fat about the size of a small marble (Fig. 11). Histologically it consisted of adipose tissue enclosed within a broad capsule of loose fibrous tissue. No lymphocytic or other cell-reaction was present.

\section{CASE 22}

A soldier, aged 23, who had suffered from myalgic pains for some time, was seen by Dr. W. S. C. Copeman, who had a nodule excised for examination. Dr. Copeman has kindly sent us this specimen for examination (Fig. 12). Histologically it consisted of lobulated fat enclosed by fibrous tissue. In the fibrous septa separating the fat lobules thickened vessels were seen, with some lymphocytic infiltration in and adjacent to the vessel wall, resembling that described by us (Gibson, Kersley, and Desmarais, 1946) in muscle, nerve, and joint fat of rheumatoid arthritis.

\section{CASE 23}

A private in the A.T.S., aged 21 , complained of the presence of nodules which were the size of peas, soft and not tender, and were situated on the back of the hands in the region of the proximal interphalangeal joints. They had been present for two years, but varied somewhat in size, she thought with the weather. She was fit, had lost no weight, and there was no clinical joint involvement. The sedimentation rate, blood count and radiographs were all normal. A small nodule was excised 

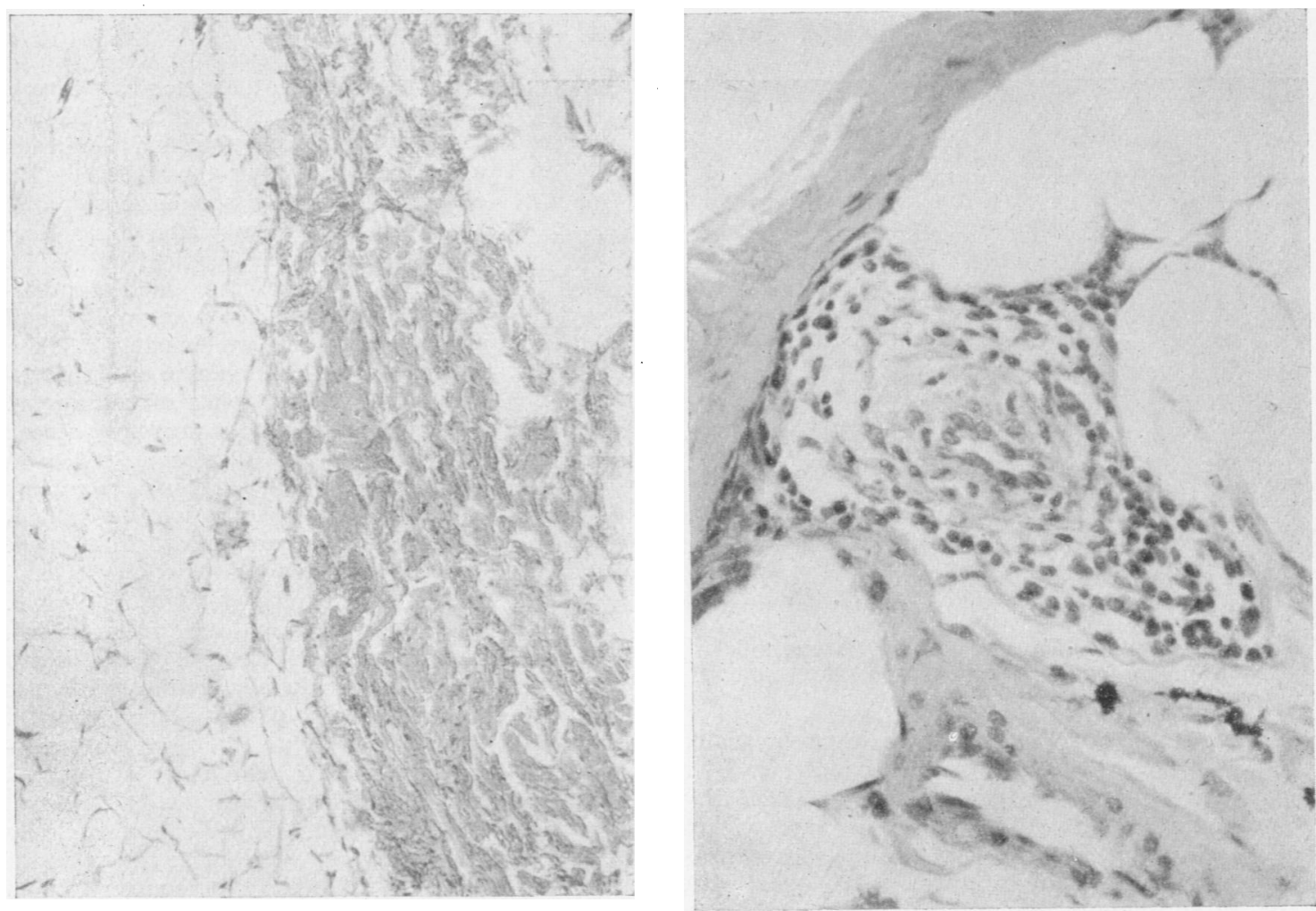

FIG. 11.

FIG. 12.

Fig. 11.-A painful nodule removed from a case of fibrositis. It consists of fat enclosed in a fibrous capsule. No round-cell reaction was seen (Case 21). Haematoxylin and eosin. $\times 100$.

Fig. 12.-Encapsulated fat removed from the lumbar region of a case of fibrositis (Case 22). In the fat adjacent to a fibrous hand is a thickwalled arteriole with a perivascular infiltration by lymphocytes. These are also present in the adventitia and media of the vessel. Haematoxylin and eosin. $\times 100$.

FIG. 13.- Nodule attached to the extensor tendon sheath of a digit (Case 23). It shows a simple fibrous structure of variable cellulårity. No histological features of rheumatoid arthritis or acute rheumatism were present. Haematoxylin and eosin. $\times 50$.

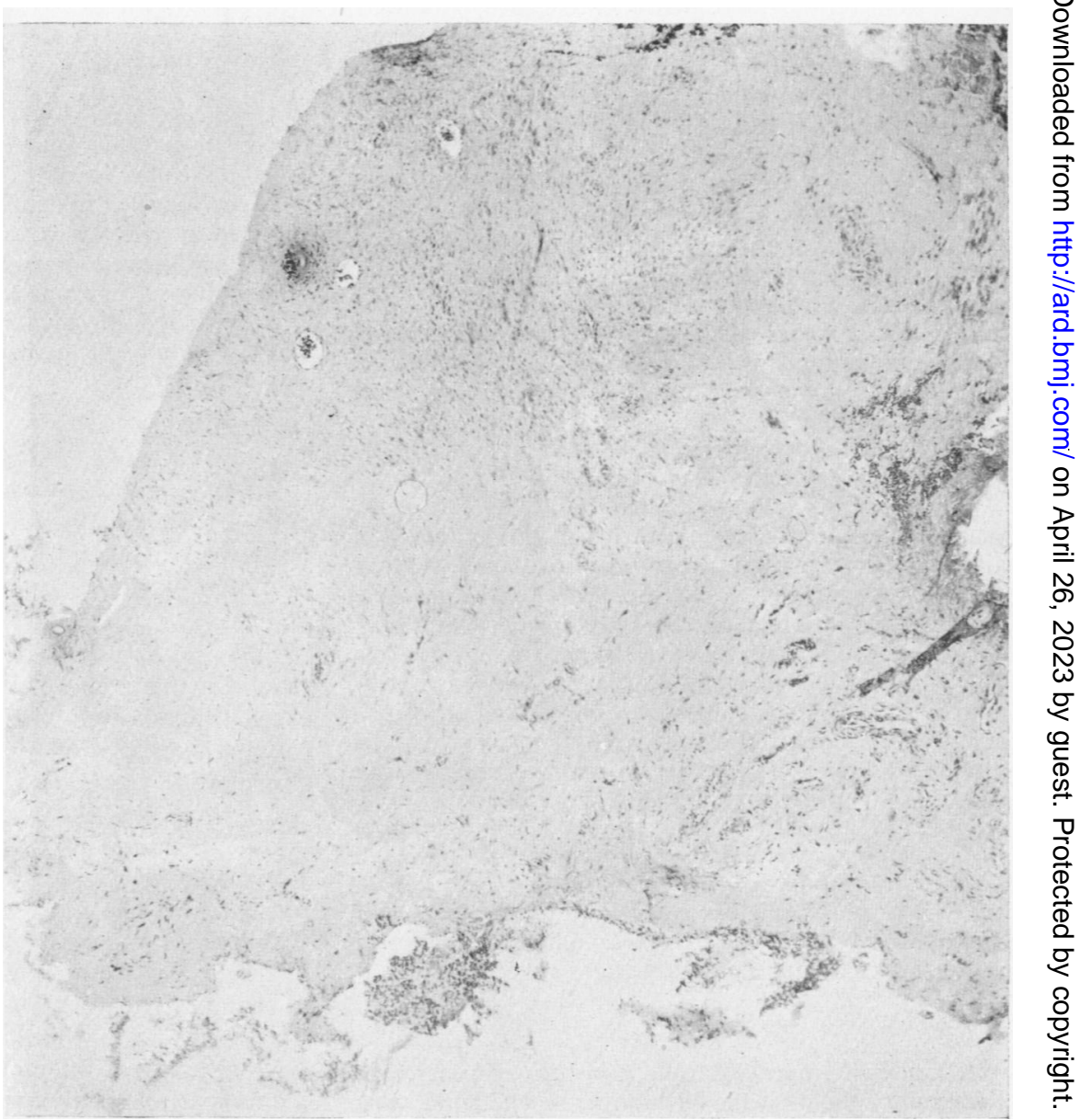

FIG. 13. 


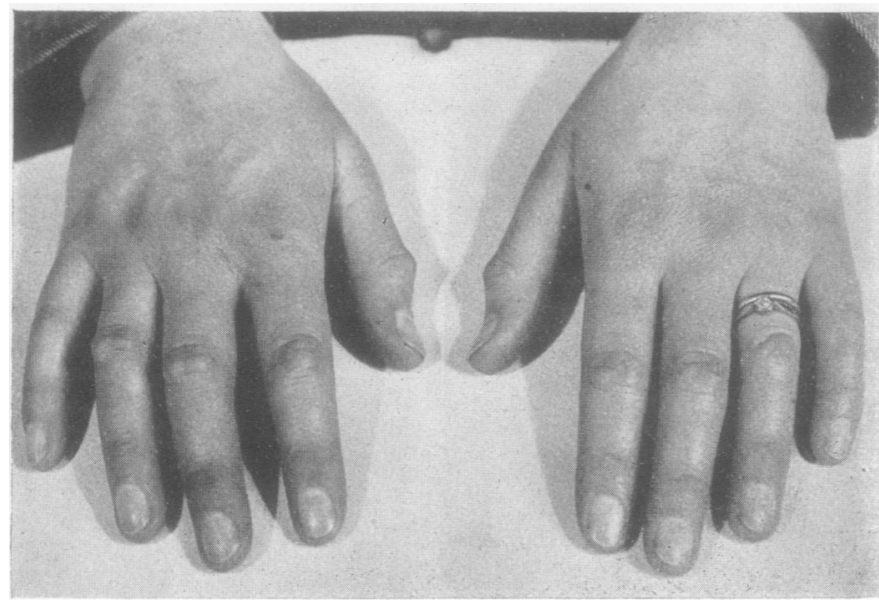

FIG. 14.-Hands of Case 27, showing fibrous nodules on the fingers. Radiographs and sedimentation rate were both normal.

she was in bed for three months. Several years later, four years before her admission, her fingers became very stiff and painful and a subcutaneous nodule appeared in the left elbow, disappearing spontaneously after two years. Six months after this a large subcutaneous nodule appeared on the left elbow, but this also disappeared spontaneously. During the last year small painful and transient pearly white nodules, the size of a small pea, had appeared on the proximal interphalangeal joints of her fingers. The appearance of these had always been associated with an increase in the pain and stiffness. There had been no recent loss of weight. On examination the patient looked quite fit, and, apart from slight limitation of movement of wrists and fingers, all the other joints were normal. The sedimentation rate, haematocrit, plasma uric acid, and blood cholesterol were normal. Radiographs of the hands showed changes of gouty type. A small

and found to be attached both to the extensor tendon sheath and the overlying skin. On section (Fig. 13) it showed a fibrous structure of varying cellularity. Numerous capillaries and small vessels were present, but there was no fibrinoid degeneration or necrosis. Leucocytic infiltration was absent. This nodule had none of the features which distinguish acute and chronic rheumatism.

\section{CASE 24}

An officer, aged 33, complained of small firm nodules on the back of the hands over the interphalangeal joints of the third and fifth digits of the right hand. They had appeared gradually and were not painful, only occasioning slight stiffness. He was fit, had no rheumatic pains, and his sedimentation rate, blood count, and radiographs were normal. On excision, one of the nodules was found to be hard and attached to the extensor tendon sheath. On section it showed almost the same appearances as Case 23. It consisted entirely of fibrous tissue, in this case of rather cellular type. Capillaries were not quite so numerous as in the previous case. Again there were none of the features of rheumatoid or acute rheumatic nodules.

CASE 25

A teacher of ballet dancing, aged 47 , who for twenty years had had a little osteo-arthritis of the left hip after an injury, had for the last two years two small nodules gradually forming on the extensor aspect of the proximal interphalangeal joints of the right hand. They were about the size of a pea, mobile and not very tender, but they occasioned some stiffness. The patient was not ill, and the C.S.S. $(80 \%)$, haematocrit $(40 \%)$, and blood uric acid $(2.5 \mathrm{mg}$. per $100 \mathrm{c.cm}$.) were almost normal. A nodule was removed for section and was found to be superficial to the extensor tendon, but extending into it. On section it consisted of dense, collagenous, fibrous tissue without any inflammatory or other leucocytic reaction. Fibroblasts were scanty. In one localized area numerous small vessels were present, some with markedly thickened walls, but the nodule was otherwise avascular. The appearances were as noted in Cases 2, 3 , and 24 .

CASE 26

A housewife, aged 31, gave a history of generalized joint pains soon after the birth of her second child, when subcutaneous nodule distal to the proximal interphalangeal joint of the third right finger was excised for examination. Underlying the skin there was a small fibrous nodule $4 \mathrm{~mm}$. $3 \mathrm{~mm}$. in size. Microscopically it consisted of fibrous tissue, with four necrotic areas of small size tending to coalesce. They consisted of an inner necrotic zone, an outer reticulated fibrinoid zone, and a cellular layer of radially arranged fibroblasts. The structure was in every way typical of the rheumatoid arthritis nodule.

\section{CASE 27}

A woman, aged 30 , seen at the British Red Cross Rheumatism Clinic, Peto Place, had had some stiffness on exercise for nine years. Three years ago nodules started to appear on the proximal interphalangeal joints. They were tender and painful only during their active growth, and after this were merely disfiguring and occasioned a little stiffness. She was fit, and the sedimentation rate ( $8 \mathrm{~mm}$.), blood uric acid ( $3.1 \mathrm{mg}$. per $100 \mathrm{c.cm}$. of blood), and radiographs of the hands were all normal. Fig. 14 shows the hands.

\section{Discussion}

Cases 1 and 2.-Cases 1 and 2 were typical of gout, both clinically and pathologically, but section of the nodule taken from Case 2 showed the presence of "foam cells" containing cholesterol (Figs. 1 and 2).

Cases 3 to 10.-These were typical of rheumatoid arthritis in an active phase, and the nodules excised all showed the histology now recognized as characteristic of that disease when it occurs elsewhere in the body.

In discussing the specificity of the rheumatoid nodule, Bennett (1943) went so far as to state that the subcutaneous nodule in rheumatoid arthritis, when present, was the most characteristic lesion seen in the condition, and he believed that it was easily distinguished in most cases from the nodule found in rheumatic fever. Dawson (1933) considered that the lesions were characteristic of the two diseases but represented different phases of the same fundamental pathological process. This did not mean that 
the similarity of the nodules could be considered as evidence that rheumatoid arthritis and rheumatic fever were aetiologically related. Collins (1939) guardedly summed up the situation by stating that " the pathologist is not in a position to dispute the dissociation of rheumatic fever and rheumatoid arthritis", and considered that nodule formation was a non-specific reaction of connective tissue. He stated that, though fibrinoid change was a characteristic and prominent feature, he was not certain whether this change was primary or secondary to proliferation of connective tissue. He quoted Werner (1938) and Wu (1937) as proving that fibrinoid swelling of collagenous tissue might result from a non-specific stimulus, whether or not the tissues were in a hypersensitive state.

Case 11.-This patient had old, burnt out, rheumatoid arthritis, and the nodule excised showed the structure of a traumatic lesion of non-specific type.

Cases 12 and 13.-These were arthritics who also showed some symptoms of hypothyroidism, and in both cases cholesterol deposits were found in the nodules (Figs. 3, 4, and 5), in addition to foci typical of a rheumatoid condition. Cholesterol was also found in the nodule excised from Case 14 (Fig. 6).

Case 12 had had typical rheumatoid arthritis, with joint involvement for nine years, the nodule having been present for eight years. The blood cholesterol has been raised to $287 \mathrm{mg}$., though at the time of the excision of the nodule, when he was taking thyroid, it had fallen to $143 \mathrm{mg}$. per $100 \mathrm{c.cm}$. The blood cholesterol in Case 13 was not estimated, and the arthritis was less typical of the rheumatoid state, though the C.S.S. was decreased. The arthritis was of four years', and the nodule of eighteen months' duration.

Case 14.-Case 14 has been described previously by us (Gibson, Kersley, and Desmarais, 1946), in connexion with muscle biopsy research in rheumatoid arthritis. At autopsy a broken-down nodule in the region of the right shoulder joint consisted largely of cholesterol deposit (Fig. 6) with certain fields containing "foam cells", very similar to those seen in one of our cases of gout (Case 2, Fig. 2).

The presence of cholesterol in certain rheumatoid nodules was mentioned by Dawson (1933). Layani (1939) recorded a case under the title "rhumatisme deformant xanthomateux" which was clinically one of rheumatoid arthritis with a sixteen years' history of joint involvement with extreme disorganization. The blood cholesterol was raised, and cholesterol deposits were found in the joints and in nodules.

Parkes Weber and Aitken (1938) reported a case of arthritis of six months' duration involving the hands, hips, and shoulders, but with normal sedimentation rate and blood uric acid and with a raised blood cholesterol. Nodules were present which contained what they described as pre-xanthoma cells or multinucleated giant cells containing fat globules.

Fletcher (1946) has described a third case, a man who had had rheumatoid arthritis for eight years and nodules for four, who had a raised, though dropping sedimentation rate $(70 \mathrm{~mm}$. to $30 \mathrm{~mm}$.) and normal blood cholesterol (135 and $154 \mathrm{mg}$. per 100 c.cm.) and blood uric acid ( $2.7 \mathrm{mg}$. per $100 \mathrm{c.cm}$.). Nodules showed necrotic areas containing cholesterol, surrounded by foam cells and giant cells lying between connective tissue-bundles. In some fields lymphocytic accumulations and eosinophils were also present. The larger vessels showed thickening of their walls and perivascular infiltration. $\mathrm{He}$ suggests that the "foam cells" are the more adult form of the pre-xanthoma cells of Parkes Weber.

In 1921 Chauffard and Troisier first described raised blood cholesterol in gout, together with amorphous cholesterol deposits in the centre of tophi and uric acid crystals at the periphery, the nodule being divided up into loculi by strands of connective tissue. It seems, therefore, that cholesterol deposition and "foam cell" formation occurs in the later stages of rheumatoid arthritis (Cases 12, 13, and 14, and those described by Layani, Parkes Weber, and Fletcher), especially when there is a tendency to hypothyroidism. In some, but not all of these cases, the blood cholesterol was raised. A similar picture can be produced in the later stages of gout (Case 2, and cases described by Chauffard).

Cases 15, 16, and 17 were clinically not quite typical rheumatoid arthritics; all, however, had nodules which on section were typical of this condition (Fig. 9). Each case showed " punched out " areas in the radiographs of the hands, which might easily have been taken for gouty changes, and Cases 16 and 17 clinically resembled gout. Case 16 gave the typical history of acute attacks followed by complete remissions over a period of twenty-one years. There had been no loss in weight and there was no anaemia. The sedimentation rate was only slightly increased, and the blood uric acid was normal. In Case 17 again there had been acute episodes, there was no loss in weight or anaemia, and the blood uric acid was increased to $5.0 \mathrm{mg}$. per $100 \mathrm{c} . \mathrm{cm}$. of blood. Neither of these cases, however, reacted dramatically to colchicum medication. They represent that group of cases sometimes diagnosed as atypical gout and sometimes as atypical rheumatoid arthritis, and which appear to link together the two syndromes. They also bear out the clinical impression that radiographs in themselves are not of diagnostic value between the two conditions. They indicate the value of histological examination of nodules as an aid to diagnosis in atypical cases.

Case 18.-This case demonstrates the difficulty occasionally experienced in drawing a sharp dividing line between rheumatic fever in the adult and rheumatoid arthritis. Case 18 started exactly like an acute rheumatism, associated with carditis and both aortic and mitral lesions. Yet he did not react to full doses of salicylates, and appears to be becoming more and more like a typical rheumatoid. The nodule removed supports this view to some extent, as, while being of the type usually seen in rheumatic 
fever, it was unusually large and more necrotic than is common (Fig. 10). Another feature of interest in this case is the fact that new nodules actually appeared and grew during a period when the sedimentation rate was normal.

Cases 19, 20, and 21.-These were cases of fibrositis. Nodules excised from the two former consisted entirely of fat (Fig. 11), bearing out the findings of Collins (1940) that biopsy of nodules on five cases of clinical fibrositis showed lipomata in three, while the fourth was a neurofibroma-the case later being confirmed as Von Rechlinghausen's disease - and the fifth showed a rheumatoid structure. This woman had some rheumatoid changes in her joints in addition to her fibrositis. Copeman and Ackerman (1944) explained fibrositis trigger points as being caused by herniation, strangulation, torsion, and oedema of fatty lobules projecting through the fascia, and they found a basic fat pattern corresponding to the common areas of tender trigger spots found in fibrositics. Our findings give some support to the view that fat may be concerned in the production of painful nodules. However, apart from the three cases quoted above, biopsy was attempted on four others. In these, nodules were palpated, but in spite of an attempt to fix them with a needle before an incision was made, no demonstrable lesion was found. This may be quoted in support of the hypothesis of Elliott (1944) that localized spasm of muscle fibres is often the cause of such tender nodes.

We can bring no evidence to support Stockman's (1920) original contention that fibrositis is due to nodes consisting of an inflammatory hyperplasia of connective tissue containing fibroblasts and serofibrinous exudate.

Case 22, from which a biopsy specimen was sent to us by Dr. Copeman, is of particular interest in that, though the nodule is essentially fatty, there are some fields where perivascular lymphocytic accumulations are present and these resemble those typically seen in rheumatoid arthritis (Fig. 12).

Cases 23, 24, 25, and 27.-These represent a syndrome, first described by Garrod, of subcutaneous nodules consisting of fibrous tissue attached to the extensor tendon sheath of the digits (Fig. 13). They occasioned only some stiffness of the hands, and there were no other rheumatic manifestations. The sedimentation rate, haematocrit reading, blood uric acid, and radiograph were all normal. A photograph of the hands of Case 27, seen by one of us at the British Red Cross Rheumatism Clinic, Peto Place, London, is illustrated in Fig. 14.

Case 26.-This case was in many ways clinically similar, but, though her sedimentation rate and haematocrit readings were normal, the radiographs showed some " punched out" areas and she gave a history of rheumatism in the past and also of nodules on the elbow which had come up and later disappeared. In this case the nodule excised from the finger showed, not a fibrous mass, but the structure usually seen in rheumatoid lesions.

\section{Summary and Conclusions}

Nodules from twenty-seven rheumatic cases have been examined, and biopsy performed in twenty-six of these. As a result they have been classified into five main groups according to both the clinical and pathological data available.

1. Two were cases of gout, and in the specimen from one of these, in addition to uric acid, cholesterol deposits were demonstrated.

2. (a) Eight cases were typical rheumatoid arthritics both clinically and in their morbid anatomy. (b) In two rheumatoid arthritics, who also showed symptoms of hypothyroidism, nodules excised contained cholesterol deposits both intra- and extracellular. "Foam cells" were seen in some fields. The literature on the subject of such deposits has been briefly discussed. (c) Nodules from three cases of atypical rheumatoid arthritis, with features clinically suggestive of gout, were shown to have the structure of rheumatoid lesions. (d) In one case who had had "rheumatism" but now presented no signs of active rheumatoid arthritis, an excised nodule showed this condition to be present.

3 . One case of rheumatic fever in an adult, who was developing features similar to rheumatoid arthritis, had a nodule which histologically suggested rheumatic fever rather than the latter diagnosis.

4. Nodules from four cases of fibrositis were examined. Three cases showed only the structure of lipomata, but in the fourth certain areas of lymphocytic infiltration were suggestive of the lesions as found in muscle, nerve, and joint tissues in rheumatoid arthritis. However, in four other cases of fibrositis, on biopsy the nodules previously palpable seemed to have disappeared.

5. Four cases are described with fibrous nodules on the fingers and hands, but with no other clinical or pathological signs of rheumatic disease.

This study emphasizes the diagnostic value of biopsy examination of nodules in the rheumatic diseases.

We should like to express our thanks to the Sidney Robinson Research Fund for the assistance in defraying expenses in connexion Research Fund for the assistance in defraying expenses in connexion
with this work, and to the remainder of hospital staff of the Royal with this Work, and to the remainder of hospital staff of the Royal
National Hospital for Rheumatic Diseases for giving us access to National Hospital for
cases under their care.

\section{REFERENCES}

Bennett, G. A. (1943). Ann. intern. Med., 19, 111.

Chauffard, A., and Troisier, J. (1921). Ann. Mid., 9, 149.

- , and Woif, M. (1923). Presse. méd., 31, 1,013.

Collins, D. H. (1937). J. Path. Bact. 45, 97.

(1939). Annals of the Rheumatic Diseases, 1, 38.

- (1940). Ibid., 2, 114.

Copeman, W. S. C., and Ackerman, W. L. (1944). Quart. J. Med., 13,37 .

Dawson, M. H. (1933). J. exp. Med., 57, 845 .

Dawson, M. H. (1933). J. exp. Med.
Elliott, F. A. (1944). Lancet, 1, 47.

Fletcher. E. (1946). Annals of the Rheumatic Diseases, 5, 88.

Gibson, H. J., Kersley, G. D., and Desmarais, M. H. L. (1946). Ibid., 5, 31 .

Layani, F. (1939). Bull. Soc. méd. Hop. Paris, 55, 343.

Stockman, R. (1920). Rheumatism and Arthritis. Edinburgh.

Weber, F. Parkes (1943). Brit. J. Derm. Syph., 55, 1. and Aitken, J. K. (1938). Lancet, 1, 198.

(1944). Annals of the Rheumatic Diseases, 4, 3

Werner, M. (1938). Arch. path. Anat., 301, 552.

Wu, T. T. (1937). Ibid., 100, 373. 